\title{
Corneal Biomechanical Assessment with Ultra-High-Speed Scheimpflug Imaging During Non-Contact Tonometry: A Prospective Review
}

This article was published in the following Dove Press journal: Clinical Ophthalmology

\author{
Pedro Manuel Baptista (iD) 1,2 \\ Renato Ambrosio Jnr (iD) $3-7$ \\ Luis Oliveira (iD) \\ Pedro Meneres (iD) 1,2 \\ Joao Melo Beirao ${ }^{1,2}$ \\ 'Ophthalmology Department, Centro \\ Hospitalar Universitário do Porto, Porto, \\ Portugal; ${ }^{2}$ Instituto de Ciências \\ Biomédicas Abel Salazar (ICBAS), Porto, \\ Portugal; ${ }^{3}$ Rio de Janeiro Corneal \\ Tomography and Biomechanics Study \\ Group, Rio de Janeiro, RJ, Brazil; \\ ${ }^{4}$ Department of Cornea and Refractive \\ Surgery, Instituto de Olhos Renato \\ Ambrósio, Rio de Janeiro, Brazil; \\ ${ }^{5}$ Department of Opthalmology, Federal \\ University of the State of Rio de Janeiro \\ (UNIRIO), Rio de Janeiro, Brazil; ${ }^{6} \mathrm{Federal}$ \\ University of São Paulo (UNIFESP), São \\ Paulo, Brazil; ${ }^{7}$ Brazilian Study Group of \\ Artificial Intelligence and Corneal \\ Analysis - BrAIN, Rio de Janeiro \& \\ Maceió, Brazil
}

Background: In recent years, increasing interest has arisen in the application of data from corneal biomechanics in many areas of ophthalmology, particularly to assist in the detection of early corneal ectasia or ectasia susceptibility, to predict corneal response to surgical or therapeutic interventions and in glaucoma management. Technology has evolved and, recently, the Scheimpflug principle was associated with a non-contact air-puff tonometer, allowing a thorough analysis of corneal biomechanics and a biomechanically corrected intraocular pressure assessment, opening up new perspectives both in ophthalmology and in other medical areas. Data from corneal biomechanics assessment are being integrated in artificial intelligence models in order to increase its value in clinical practice.

Objective: To review the state of the art in the field of corneal biomechanics assessment with special emphasis to the technology based on ultra-high-speed Scheimpflug imaging during non-contact tonometry.

Summary: A meticulous literature review was performed until the present day. We used 136 published manuscripts as our references. Both information from healthy individuals and descriptions of possible associations with systemic diseases are described. Additionally, it exposed information regarding several fields of ocular pathology, from cornea and ocular surface through areas of refractive surgery and glaucoma until vascular and structural diseases of the chorioretinal unit.

Keywords: cornea, corneal biomechanics, Corvis, ultra-high speed Szcheimpflug camera

\section{General Biomechanics}

Biomechanics is often defined as "mechanics applied to biology" and has contributed significantly to understanding anatomic human behavior in different specialities of medicine. In the last fifty years, the concept of biomechanics evolved in the setting of human diseases, injuries and response to treatment. Nevertheless, the study of human body biomechanics did not meet sufficient accuracy and predictability to contribute significantly in clinical practice for many years. ${ }^{1}$

The term biomechanics can be defined as the quantification of the complex mechanical behaviour of biological structures, and its application to better understand physiology and physiopathology in order to improve diagnosis, prognosis and treatment of many disorders. ${ }^{2}$

Biological tissues can have multiple and complex responses when facing stress and strains. Thus, models trying to describe it have to consider the heterogeneous
Correspondence: Pedro Manuel Baptista Centro Hospitalar Universitário do Porto, Largo Prof. Abel Salazar, Porto, 4099-00I, Portugal

Tel +35I-917868372

Email pedroyybaptista@gmail.com 
non-linear and anisotropic character that is not completely stable across different points, different timings and different patients. $^{3}$

\section{Corneal Biomechanics}

Assessing the biomechanical response of living tissue is complex and demands knowledge of some basic concepts of mechanical engineering: ${ }^{4}$

- Elastic modulus or Young's modulus: describes how much a load will deform the material under specific conditions. ${ }^{5}$ The material deformation is expressed as a strain and will lead to an internal response within the material (stress). Young's modulus is depicted by the slope of the stress-strain plot. The greater the slope is, the higher the modulus and the stiffer the material are such that greater force is required to deform a more rigid material.

- Viscoelasticity: implies that the material behavior is strain rate (time) dependent and is different during loading and unloading phases, differently from pure elastic materials, that have symmetric loadingunloading behaviour. More specifically, the stressstrain pathways by which viscoelastic materials return to the steady state are dependent on loading rates and the difference between loading and unloading behavior is characterized by Hysteresis, ${ }^{6}$ which represents the amount of energy dissipated during the loading-unloading process, usually as thermal energy. Viscoelasticity is an intrinsic characteristic of every living tissue.

The cornea has been recognized for a long time as an anisotropic composite with nonlinear viscoelastic properties rather than a linear elastic structure because its properties are determined by the interaction of diverse materials like collagen and a polyanionic, hydrophilic ground substance and are not directionally uniform. ${ }^{7}$ The anterior stroma and Bowman membrane are the chief collagenous layers, providing the majority of the cornea's tensile strength.The viscoelastic behaviour its provided by the ground substance. ${ }^{8,9}$

Understanding these concepts and how they apply to the cornea and the eye as a whole, highlights why it is so difficult to define the cornea biomechanically with a single number or scale. Moreover, the distinct features found when the center is compared to the periphery and when the anterior cornea is compared to the posterior regions make biomechanical characterization an even more challenging task.

Corneal biomechanics have been assessed through Extensiometry in vitro studies by measuring stress-strain and Young's modulus in isolated corneas. ${ }^{10}$ Nonetheless, the impossibility of performing this test in vivo and the artifact resulting from testing corneal tissue outside of its native curved configuration has prompted accelerated efforts to develop nondestructive, noninvasive tools for clinical biomechanical property measurement.

In recent years, the assessment of corneal biomechanics has been the subject of increasing interest both in the detection of ectasia susceptibility and in the prediction of corneal responses to surgical or therapeutic interventions. $^{11-15}$ Additionally, as intraocular pressure (IOP) has been shown to be influenciated by corneal biomechanical behaviour, its role in the prediction of glaucoma susceptibility is another area of interest. ${ }^{16}$

The first commercially available device capable of evaluating the cornea's biomechanical features was the Ocular Response Analyzer ${ }^{\circledR}$ (ORA, Reichert, Inc., Depew, NY), which quantifies the dynamics of corneal deformation and recovery as an indicator of corneal hysteresis $(\mathrm{CH})$, through a high-speed air-puff. ${ }^{17} \mathrm{CH}$ is the difference between the ingoing and outgoing applanation pressures $(\mathrm{P} 1-\mathrm{P} 2)$ and represents the energy loss due to viscous damping in the cornea and extra-corneal structures. Additionally, it can measure the overall elastic resistance of the cornea - corneal resistance factor (CRF) which is a formula derived from the $\mathrm{CH}$, with an incorporated empirically determined adjustment factor $(\mathrm{k})$ to $\mathrm{P} 2$ $(\mathrm{CRF}=\mathrm{P} 1-\mathrm{kP} 2) .{ }^{18-20}$ However, as $\mathrm{CH}$ could be associated with low or high elasticity depending on the viscosity, there is not a direct relationship between the $\mathrm{CH}$ and the Young's modulus ${ }^{21}$ and conclusions from studies using the ORA should be considered cautiously. Another main limitation is that there is a significant variability in $\mathrm{CH}$ and CRF among normal healthy individuals that can be influenced by the variability of IOP in the same population. ${ }^{22}$

The Corvis $\mathrm{ST}^{\circledR}$ (Corvis, Oculus Optikgeräte $\mathrm{GmbH}$, Wetzlar, Germany) is a non-contact tonometer that employs a similar air puff perturbation and has been commercially available since 2011 . However, it has coupled an ultra-high-speed Scheimpflug camera that records the deformation process at 4330 frames/second along an $8 \mathrm{~mm}$ horizontal corneal cross-section during corneal deformation. $^{23,24}$ Analysis of the images gives insight into the infrared signal behavior observed with the ORA, 
and, because direct analysis of shape is possible, provides additional opportunities for a more direct derivation of biomechanical response. ${ }^{25,26}$ Contrary to the ORA, the Corvis does not vary the air puff pressure from measurement to measurement, and differences in applied force might confound attempts to directly compare results obtained with these two instruments. ${ }^{27}$ Additionally, the associated Scheimpflug principle allowed the measurement of several new parameters, usually referred as Dynamic Corneal Response analysis (DCR), and the biomechanically corrected intraocular pressure (bIOP), opening up new perspectives within the aforementioned fields. The main limitation of this device is that the measurements are made only in a single $8 \mathrm{~mm}$ horizontal corneal cross-section, which could eventually be overcome through an analysis on several cross-sections across the entire $360^{\circ}$. Figure 1 represents an example of a print-out showing the corneal shape within different timepoints and several biomechanical parameters and Table 1 describes all the parameters derived from the Corvis with explanation.
Other techniques that combine corneal deformation analysis with high-speed imaging have been proposed, such as Supersonic shear-wave imaging, ${ }^{28}$ Surface wave elastometry $^{29}$ or Elastography with gonioscopy lens, ${ }^{30}$ but are not currently applied in vivo.

Another approach is the measurement of corneal biomechanics in vivo through the analysis of light scatter and mapping the biomechanical state of the cornea with 3-D capability, determining intrinsic viscoelastic properties decoupled from structural information and applied pressure, through Brillouin optical microscopy technology. ${ }^{15}$ However, besides the demonstrated impact of age on corneal biomechanics and differences between normal and keratoconic corneas, the accuracy of the reported findings is relatively weak in this setting and still needs further development. ${ }^{31}$

\section{Corneal Biomechanics in Healthy Individuals}

Ocular structures are known to be different among different populations across the world and some studies have

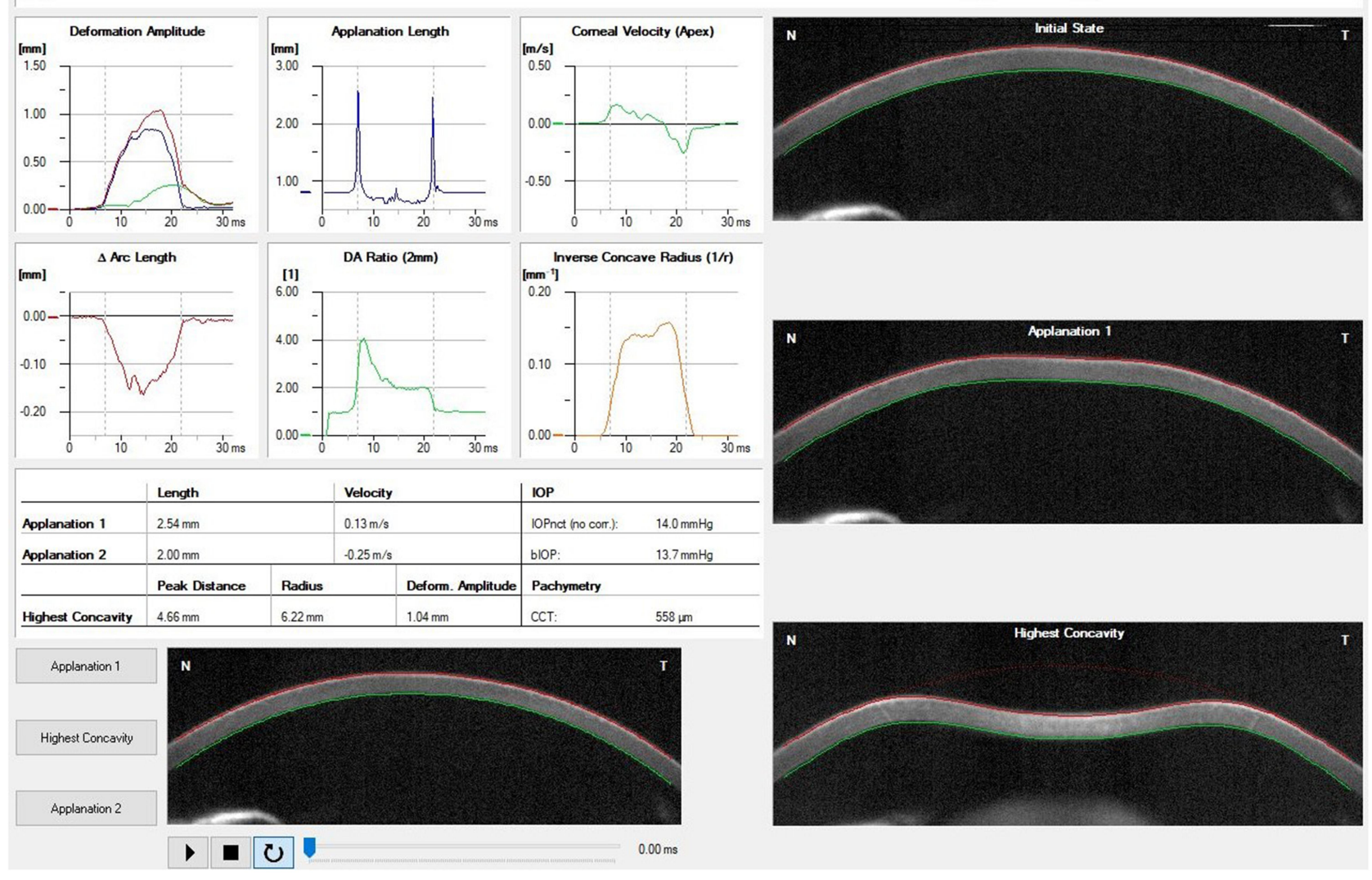

Figure I Example of a print-out from the Corvis $S T^{\circledR}$ describing the corneal, shape within different timepoints and several biomechanical parameters.

Notes : Copyright @202I. Reproduced from Baptista PM, Marta AA, Marques JH, Abreu AC, Monteiro S, Menéres P, Pinto MDC. The Role of Corneal Biomechanics in the Assessment of Ectasia Susceptibility Before Laser Vision Correction. Clin Ophthalmol. 202 1;15:745-758. ${ }^{146}$ 
Table I Ultra-High-Speed Scheimpflug Camera-Based Corneal Biomechanical Parameters with Explanation

\begin{tabular}{|c|c|c|}
\hline Parameters & Abbreviations & Explanation \\
\hline $\begin{array}{l}\text { Corvis-derived non-contact } \\
\text { tonometry IOP }[\mathrm{mmHg}]\end{array}$ & clOP & Corvis-derived intraocular pressure \\
\hline $\begin{array}{l}\text { Corvis-derived central corneal } \\
\text { thickness }[\mu \mathrm{m}]\end{array}$ & сCCT & Corvis-derivated central corneal thickness \\
\hline Ist Generation Parameters & Abbreviations & Explanation \\
\hline Deformation Amp. Max [mm] & MaxDefoA & $\begin{array}{l}\text { Corneal deformation amplitude during MaxDT, as the sum of corneal deflection amplitude } \\
\text { and MaxWEM }\end{array}$ \\
\hline Al Time $[\mathrm{ms}]$ & AIT & Time from the measurement beginning to the first applanation moment \\
\hline Al Velocity $[\mathrm{m} / \mathrm{s}]$ & AIV & Velocity of the corneal apex during the first applanation \\
\hline A2 Time $[\mathrm{ms}]$ & $\mathrm{A} 2 \mathrm{~T}$ & Time from the measurement beginning to the second applanation moment \\
\hline A2 Velocity $[\mathrm{m} / \mathrm{s}]$ & $\mathrm{A} 2 \mathrm{~V}$ & Velocity of the corneal apex during the second applanation \\
\hline HC Time $[\mathrm{ms}]$ & HCT & $\begin{array}{l}\text { Time from the measurement beginning to the moment of reaching the highest concavity } \\
(\mathrm{HC})\end{array}$ \\
\hline Peak Dist. [mm] & HCPD & Distance between the corneal peaks at the $\mathrm{HC}$ \\
\hline Radius $[\mathrm{mm}]$ & HCR & Radius of corneal curvature during the $\mathrm{HC}$ \\
\hline Al Deformation Amp. [mm] & AIDefoA & $\begin{array}{l}\text { Corneal deformation amplitude during AI, as the sum of corneal deflection amplitude and } \\
\text { MaxWEM }\end{array}$ \\
\hline HC Deformation Amp. [mm] & HCDefoA & $\begin{array}{l}\text { Corneal deformation amplitude during } \mathrm{HC} \text {, as the sum of corneal deflection amplitude and } \\
\text { MaxWEM }\end{array}$ \\
\hline A2 Deformation Amp. [mm] & A2DefoA & $\begin{array}{l}\text { Corneal deformation amplitude during } \mathrm{A} 2 \text {, as the sum of corneal deflection amplitude and } \\
\text { MaxWEM }\end{array}$ \\
\hline AI Deflection Length $[\mathrm{mm}]$ & AIDL & Horizontal length of the flattened cornea at the Al \\
\hline HC Deflection Length [mm] & $\mathrm{HCDL}$ & Horizontal length of the flattened cornea at the $\mathrm{HC}$ \\
\hline A2 Deflection Length [mm] & A2DL & Horizontal length of the flattened cornea at the A2 \\
\hline Al Deflection Amp. [mm] & AIDA & $\begin{array}{l}\text { Corneal deflection amplitude during AI, determined as the displacement of the corneal } \\
\text { apex in relation to the initial state without the MaxWEM quantification }\end{array}$ \\
\hline HC Deflection Amp. [mm] & HCDA & $\begin{array}{l}\text { Corneal deflection amplitude during } \mathrm{HC} \text {, determined as the displacement of the corneal } \\
\text { apex in relation to the initial state without the MaxWEM quantification }\end{array}$ \\
\hline A2 Deflection Amp. [mm] & A2DA & $\begin{array}{l}\text { Corneal deflection amplitude during } A 2 \text {, determined as the displacement of the corneal } \\
\text { apex in relation to the initial state without the MaxWEM quantification }\end{array}$ \\
\hline Deflection Amp. Max [mm] & MaxDA & $\begin{array}{l}\text { Corneal deformation amplitude during MaxDT, as the sum of corneal deflection amplitude } \\
\text { and MaxWEM }\end{array}$ \\
\hline Deflection Amp. Max [ms] & MaxDT & Moment of the maximum deformation, during the oscillatory phase near $\mathrm{HC}$ \\
\hline $\begin{array}{l}\text { Whole Eye Movement Max } \\
{[\mathrm{mm}]}\end{array}$ & MaxWEM & Amplitude of the Maximum whole eye movement \\
\hline Whole Eye Movement Max [ms] & MaxWEMT & Time at which occurs the amplitude of the Maximum whole eye movement (near A2) \\
\hline Al Deflection Area [mm2] & AIDArea & Deflection area in Al \\
\hline
\end{tabular}

(Continued) 
Table I (Continued).

\begin{tabular}{|c|c|c|}
\hline Parameters & Abbreviations & Explanation \\
\hline HC Deflection Area [mm2] & HCDArea & Deflection area in $\mathrm{HC}$ \\
\hline A2 Deflection Area [mm2] & A2DArea & Deflection area in $\mathrm{A} 2$ \\
\hline Al dArc Length [mm] & AldArcL & Delta arc length of corneal surface in Al \\
\hline $\mathrm{HC}$ dArc Length $[\mathrm{mm}]$ & $\mathrm{HCdArcL}$ & Delta arc length of corneal surface in $\mathrm{HC}$ \\
\hline A2 dArc Length [mm] & $\mathrm{A} 2 \mathrm{dArcL}$ & Delta arc length of corneal surface in A2 \\
\hline dArcLengthMax $[\mathrm{mm}]$ & MaxdArcL & Delta arc length of corneal surface in MaxDT \\
\hline 2nd Generation Parameters & Abbreviations & Explanation \\
\hline Max InverseRadius $\left[\mathrm{mm}^{\wedge}-\mathrm{I}\right]$ & MIR & I/HCR \\
\hline DA Ratio Max (2mm) & DARM2 & Ápex MaxDA/MaxDA at $2 \mathrm{~mm}$ from the ápex \\
\hline PachySlope $[\mu \mathrm{m}]$ & $\mathrm{PqS}$ & Peripheric (8mm horizontal) pachymetry/Ápex pachymetry \\
\hline DA Ratio Max (Imm) & DARMI & Ápex MaxDA/MaxDA at Imm from the ápex \\
\hline $\begin{array}{l}\text { Ambrosio Relational Thickness } \\
\text { (horizontal } 8 \mathrm{~mm} \text { ) }\end{array}$ & ARTh & Ambrosio Relational Thickness in the horizontal $8 \mathrm{~mm}$ cornea of the image \\
\hline Biomechanically-corrected IOP & bIOP & IOP adjusted for biomechanical parameters \\
\hline Integrated Radius $\left[\mathrm{mm}^{\wedge}-\mathrm{I}\right]$ & IR & Area under the curve of the $\mathrm{I} / \mathrm{HCR}$ function \\
\hline Stiffness parameter in Al & SP-AI & Air puff pressure - bIOP/AIDA \\
\hline Stress Strain Index & SS-I & $\begin{array}{l}\text { Finite element modeling algorithm for the estimation of the non-linear in vivo biomechanical } \\
\text { behaviour in corneal with normal topography }\end{array}$ \\
\hline Corvis biomechanical index & $\mathrm{CBI}$ & $\begin{array}{l}\text { Exponential function score made through a logistic regression analysis of } 6 \text { parameters (SP- } \\
\text { AI, DARMI, DARM2, ARTh, AIV and MaxDefoA) and adjusted for IOP and CCT to } \\
\text { describe ectasia risk }\end{array}$ \\
\hline $\begin{array}{l}\text { Tomographic and biomechanical } \\
\text { Index }\end{array}$ & TBI & $\begin{array}{l}\text { Generated by the random Forest method with leave-one-out cross-validation, including } \\
\text { tomographic and biomechanical parameters, to detect ectasia susceptibility }\end{array}$ \\
\hline
\end{tabular}

described corneal biomechanical properties among different adult ${ }^{32-34}$ and children ${ }^{35}$ populations.

The age-related changes in corneal stroma were studied ex vivo and the proved increase in spacing between collagen fibers can be hypothesised to be linked with increasing natural sun-related collagen crosslinking over the years. ${ }^{36}$ Recent studies with Corvis reported ${ }^{37}$ alterations in corneal biomechanics with age, but there is still controversy in literature. ${ }^{38,39}$ Other factors like axial length, ${ }^{40,41}$ height/weight, higher meat or vitamin E intake $^{38}$ or even fasting ${ }^{42}$ and dry eye ${ }^{43}$ were shown to predict corneal biomechanical status, but the evidence is still poor. Additionally, there is some evidence of the relationship between corneal hydration status and biomechanical properties. However, data come from artificially created conditions, and the modalities of study are not well suited to in vivo applications. ${ }^{44}$

Therefore, deeper knowledge of the corneal biomechanical response in relation with populations in different latitudes, different lifestyles or other body biometric parameters would be invaluable for the prediction of disease progression or treatment outcomes regarding clinical situations where the biomechanical aspects of an eye are important. Thus, it is of utmost importance to establish normative data to value the results within different ocular or systemic diseases.

It is well known the biomechanical effect of UV-A/ riboflavin (B2 Vitamin) corneal crosslinking (CXL). ${ }^{45}$ However, there is no scientific evidence of the daily-life sun exposure, solarium, or oral B2 vitamin intake as predictors of corneal biomechanics. 


\section{Corneal Biomechanics and Systemic Disease}

Investigation upon the impact of diabetes on corneal biomechanical parameters and IOP measurements has been initiated some years ago with the ORA but the results were rather controversial. ${ }^{46,47}$ Recently, the complex data from the Corvis are been added and confirmed biomechanically altered corneas ${ }^{48}$ but its role, namely in IOP measurements in these patients, is not yet established. Vascular walls share some of the stromal corneal components ${ }^{49}$ and there is evidence in the literature about the importance of vascular type I collagen regulation, for both vessel development and remodeling in pathologic states like atherosclerosis and pulmonary hypertension. ${ }^{50}$ As type 1 collagen is the main type present in the corneal stroma (but also other components are shared between the cornea and vascular walls) the complex study of corneal biomechanics by the Scheimpflug technology can be a potential non-invasive surrogate marker of differential vascular responses to the aggression of diabetes and have a role in prognosis. As the complex regulation in the genesis of diabetic macular edema is still not completely clear, there are not a perfect approach ${ }^{51}$ and many factors, other than VEGF can play a role, including the individual vascular wall structure. Besides the reported association between retinal vascular caliber and corneal biomechanical properties, ${ }^{52}$ data in this setting are scarce and there are no descriptions about the above inferences in literature.

The spectrum of auto-immune collagen vascular diseases (CVD) is wide and the majority of those can affect the eye. Besides the little knowledge about the association of corneal biomechanics and these diseases, few studies tried to assess it with the ORA, namely in Systemic Lupus Erythematosus (SLE) or Rheumatoid Arthritis (RA). ${ }^{53,54}$ More recently, some association between disease activity was postulated through the Corvis, analysis. ${ }^{55}$ In hereditary CVD like Marfan Syndrome, besides the biomechanical alterations founded, it was associated with an increased risk of ectopia lens. ${ }^{56}$

\section{Corneal Biomechanics and Ocular Surface}

Ocular surface disease (OSD) is an increasingly prevalent disorder, due to the current lifestyle and a greater autoimmune burden in the population. ${ }^{43}$ Recently, alterations in corneal biomechanics using Scheimpflug technology were reported in OSD subjects, ${ }^{57}$ more pronounced when associated with an auto-immune disease like Sjogren Syndrome. ${ }^{58}$ However, data are scarce and causality relationships remain controversial, as the biomechanical alterations can have some inflammatory basis or the eye rubbing due to eye discomfort in OSD can lead to altered corneas. Another issue that remains to be proven is the possible direct effect of the tear film in the air puff measurements. Given this, the study of DCRs in these eyes can introduce valuable information within the areas of keratoconus and refractive surgery screening.

Contact lenses (CL) are a common option in the correction of an increasingly broad spectrum of refractive errors. While soft contact lens are appropriate for most of the mild and moderate refractive errors in otherwise healthy eyes, rigid-gas permeable contact lenses (RGP$\mathrm{CL})$ are a common non-surgical option in keratoconus patients which do not reach good visual quality by spectacles, through its regularization effect on corneal surface. ${ }^{59}$ Although the optimization of material properties has greatly improved its oxygen permeability and comfort and greatly reduced the incidence of side reactions, both types constitute aggression to the ocular surface. This is particularly important in keratoconus patients with longterm utilization of RGP-CL, in which is still not concluded if the chronic hypoxia stimulation, the change of tear components, the proinflammatory effect on the ocular surface, and the induction of apoptosis can promote the progression of the disease. ${ }^{60}$

There are few reports in the literature showing shortterm $^{61}$ but not long-term biomechanical alterations associated with soft $\mathrm{CL}^{62}$ with the ORA and short-term alterations associated with RGP-CL with the Corvis. ${ }^{63}$ However, more consistent data are needed, to generate consensus regarding the issue of disease progression in RGP-CL wearers.

\section{Corneal Biomechanics and Corneal Ectatic Diseases}

The knowledge regarding corneal ectatic diseases and its management had evolved in the last decades. ${ }^{64}$ Currently, the mainstays of corneal ectasia are the biomechanical failure and stromal thinning, causing corneal bulging with subsequent visual impairment due to irregular astigmatism. Moderate and advanced stages are easily recognized, but the identification of mild or subclinical forms remains a challenge. ${ }^{15}$ However, in the last years, the evolution on the assessment of corneal biomechanics 
allowed important advances in the diagnosis, staging, and prognosis of ectatic corneal diseases, such as keratoconus and pellucid marginal degeneration. ${ }^{65-67}$

Understanding the cornea's biomechanical behavior is being established for the detection of subclinical $\mathrm{KC}$ as well as for detection of ectasia progression, while changes in topography are subtle. ${ }^{68}$

Although Corvis-derived first-generation parameters did not improve the performance obtained through the pressure-derived ORA data for discriminating healthy and $\mathrm{KC}$ eyes, ${ }^{69}$ the Scheimpflug camera analysis enabled the development of new integrated parameters that consider the IOP influence on the DCR parameters. More recently, these were combined with tomographic parameters creating a new Index called Tomographic and Biomechanical Index (TBI) with proven superior accuracy for the detection of ectatic disease or even ectasia susceptibility. ${ }^{70}$

Although recent evolutions, more data are needed to validate this Index within other populations and to understand its practical value, namely at the level of screening in family members and early diagnosis of disease progression. Additionally, biomechanical properties may be of great value in the future era of genotype-phenotype disease characterization.

\section{Corneal Biomechanics and Corneal Crosslinking}

Corneal collagen cross-linking (CXL) has a stiffening and stabilizing effect on corneal stroma, due to the induced changes in the physicochemical properties of the collagen and increased resistance to enzymatic degradation. Through several protocols, mainly usingradiation with wavelength within the ultraviolet spectrum and riboflavin as the photosensitizer, has been used increasingly to stabilize the cornea and stop the progression of keratoconus. ${ }^{71}$

Few studies try to measure the CXL effect on corneal biomechanics with the ORA. While some reported no statistically significant differences, ${ }^{72,73}$ others found mild evidence of the effect. ${ }^{74,75}$ Regarding the Corvis, in the same line, there were no consistent proves of evident alterations in former studies, ${ }^{76}$ including comparisons between different protocols. ${ }^{77,78}$ However, a recent study showed some consistent evidence of differences, mainly in Corvis-derivated second applanation parameters. ${ }^{45}$ Device repeatability issues due to inferior waveform quality in keratoconus eyes are a limitation in the ORA assessments, but the broadcornea approach carried out by both devices contrasts with the theoretical most localized effect of CXL, being a possible factor that can limit the results assessment. ${ }^{45}$ With the Corvis this could eventually be overcome through an analysis on several cross-sections across the entire $360^{\circ}$ and/or analyzing only the ectatic area in more advanced disease stages. Since Riboflavin-dextran solution can be associated with short-term alterations in ex vivo corneal biomechanics due to altered hydration status, ${ }^{79}$ it can be hypothesized as another contributing factor. However, data are still scarce and the validity and importance of such findings are unclear, maintaining controversy within this issue.

\section{Corneal Biomechanics and Intracorneal Ring Segments}

The implantation of intrastromal corneal ring segments (ICRS) in patients with keratoconus is a minimally invasive and reversible surgical procedure in which an "arcshortening effect" on the corneal lamellae flattens the central cornea, reducing low and high order aberrations, with reported improvements in vision quality and increased tolerance to contact lenses in some patients. ${ }^{80}$ The ICRS has evolved allowing to increase the customization in the treatment of eyes with asymmetric astigmatism. However, even though some longterm studies reporting the stability of the surgical procedure, ${ }^{81,82}$ it is still controversial if the new implant-related steady-state in the forces along the stroma has a role in biomechanical stabilization, and/or if it makes the patient less prone to eye rubbing a more flatten cornea. A recent study showed no consistent changes in biomechanical properties six months following ICRS implantation ${ }^{83}$ but data are scarce.

There are several reports on literature showing good refractive and functional results after the implantation of ICRS. ${ }^{80,84,85}$ Nevertheless, as a new corneal shape is created, the final functional result is not completely predictable.$^{80}$ The idea of better functional results in softer corneas was reported years ago with the ORA ${ }^{86,87}$ but a recent study highlighted the low predictive value of corneal biomechanics in comparison with other presurgical characteristics. ${ }^{88}$

Both the controversies regarding a possible halting effect and the search for more consistent predictors of functional outcomes to optimize the nomograms of ICRS 
need more data from corneal biomechanics, namely through Scheimpflug technology.

\section{Corneal Biomechanics and Corneal Grafts}

The differential effect of different corneal transplantation techniques in corneal biomechanics has been described with the ORA. In keratoconus eyes, increments in corneal stiffness after PK and DALK were reported. ${ }^{89}$ In PBK eyes, normal values after $\mathrm{DSAEK}^{90}$ or $\mathrm{DMEK}^{91}$ were reported with the ORA. Recently, differences in DCR between the four techniques were highlighted through the Scheimpflug technology. ${ }^{92,93}$ Additionally, differences between uncorrected IOP and bIOP were exposed in postkeratoplasty eyes. ${ }^{93}$ However, data regarding DCR and bIOP from the Scheimpflug technology are still scarce and the role of biomechanics in the IOP assessment after these procedures is still not established.

The role of the Bowman layer in corneal biomechanics is not well established. It is reasonable to think that the Bowman layer has a role, but there is some recent evidence of the opposite, ${ }^{94}$ which can call into question the promising role of Bowman layer transplantation for keratoconus. ${ }^{95}$

\section{Corneal Biomechanics and Other Procedures}

Phacoemulsification cataract surgery is the most performed surgical intervention worldwide. Despite the evolution in the procedure, the corneal incision is still the most performed approach. There is evidence of corneal stiffness decrease in the short follow-up after cataract surgery with the subsequent falsely low IOP measurements. ${ }^{96,97}$ This finding is of particular interest in the evaluation of postoperative IOP, particularly for glaucoma patients, and when assessing the effectivity of a combined procedure with glaucoma surgery, namely with the new minimally invasive glaucoma surgery devices. However, there is a lack of evidence of the biomechanical status in the long term after cataract surgery.

The implantation of phakic intraocular lenses is a common procedure nowadays, with the new lens options overtaking the limitations of former ones. Due to technological evolution, the indications increased and nowadays these lenses are good options in cases of high myopia or stable keratoconus. Given the issues of increased glaucoma risk and biomechanical progressive alterations, respectively, it is of utmost importance to study the effect of the procedure in the DCR and the role of bIOP in these eyes. A rapid normalization after posterior chamber PIOLs implantation was reported, ${ }^{98}$ but data are scarce, or absent regarding the anterior chamber PIOls, more prone to corneal and glaucomatous complications.

\section{Corneal Biomechanics and Corneal Refractive Surgery}

Corneal ectasia after corneal laser vision correction (LVC) procedures is rare ${ }^{99}$ but can be devastating in previously healthy eyes in young people. The actual incidence is decreasing, ${ }^{100}$ due to the evolution both in the laserassociated technology and the progress made in the preoperative risk evaluation.

Both the baseline biomechanical status of the cornea, the structural impact of the procedure and possible major or recurrent mild trauma after surgery are the main predictors of biomechanical decompensation leading to ectasia progression after LVC. ${ }^{70}$ Thus, side by side with the evolution in laser-associated technology, the exclusion of eyes with mild or subclinical forms of corneal ectasia has been crucial for the high safeness of the procedure. ${ }^{101}$

After the ectasia risk score system (ERSS) validation, including the residual stromal bed (RSB) concept, ${ }^{102}$ the study of the structural impact from the procedure evolved and the percent tissue altered (PTA) became the main parameter associated with an increased risk. ${ }^{103,104}$ In 2018, after a review of more than 30,000 LASIK cases, Bohac et $\mathrm{al}^{105}$ concluded that, although the aforementioned widely accepted risk factors were the most prevalent in cases of corneal ectasia after LASIK, there is a need to augment the accuracy with higher sensitivity and specificity, since ectasia has been reported in cases without any of these risk factors.

Since a focal reduction in corneal elastic modulus precipitates the cycle of biomechanical decompensation, as proposed by Roberts et al, ${ }^{106}$ it was expected that biomechanical assessment would enhance the overall accuracy in the identification of mild forms of ectatic corneal disease. ${ }^{19}$ Although the first original set of Corvis corneal deformation parameters had a relatively poor performance in distinguishing healthy and keratoconus (KC) eyes, in 2014, a parameter combining deformation response parameters with corneal thickness profile and developed through logistic regression analysis was introduced - the 
Corneal biomechanical Index $(\mathrm{CBI}){ }^{107}$ However, to address ectasia risk there was a need to go further, and Ambrósio et $\mathrm{al}^{70}$ combined data from the corneal deformation response, including $\mathrm{CBI}$, with tomographic data, through artificial intelligence and originated a more accurate index, the new Tomographic and Biomechanical Index (TBI).

\section{Corneal Biomechanics and Corneal Dystrophies}

Some data associated Fuchs endothelial corneal dystrophy (FECD) with reduced $\mathrm{CH}$ and $\mathrm{CRF}{ }^{108}$ Additionally, the potential role of biomechanically corrected IOP measurements in FECD patients after posterior lamellar keratoplasty was highlighted. ${ }^{109}$

However, data are still scarce, particularly those associated with Corvis, for this and other corneal dystrophies.

\section{Corneal Biomechanics and Various Types of Glaucoma}

Glaucoma is the leading cause of irreversible blindness worldwide, affecting more than 70 million people and estimated to affect about 110 million in $2040 .{ }^{110}$

The progressive and permanent vision loss results from optic nerve damage and loss of retinal ganglion cells (RGC). Reducing effectively and continuously intraocular pressure (IOP) remains the only proven conservative method for preventing and delaying the progression of glaucomatous visual impairment. ${ }^{111}$ However, the irreversible sustained injury of the optic nerve, gradual narrowing of the visual field, and progressive loss of visual function despite average IOP below normal levels (normotensive glaucoma) suggests that other important factors play a role. ${ }^{112}$ The isolated officebased IOP measurement is recognized as a major limitation in glaucoma management today, and although not yet clinically established, continuous measurement strategies including night time are assumed as an important step forward. $^{113}$

The classical IOP assessment through the Goldman applanation tonometry is based on the Imbert Fick principle, which is directly dependent on corneal biomechanics. Growing evidence suggests that biomechanical factors are involved in the pathogenesis of glaucoma. ${ }^{114-118}$
According to the mechanical hypothesis of glaucoma, the lamina cribrosa is the main location of damage to the retinal nerve fibers. Additionally, in recent years, the evidence of biomechanical properties of the sclera and scleral lamina cribrosa (LC) acting as major determinants of biomechanical behaviour of the optic nerve head $(\mathrm{ONH})$ is getting more consistent $^{119-121}$ highlighting its important role for glaucomatous damage inferred years before. ${ }^{122,123}$ In fact, as cornea, sclera and LC are continuous sheaths, constituted by the same components, the hypothesis of biomechanical properties of this unit determining the response of the $\mathrm{ONH}$ to IOP can be an explanatory factor to the amount of axonal nerve damage even with IOP within the normal range in asymmetrical normal-tension glaucoma. ${ }^{124}$

In the last years, the role of corneal biomechanics in glaucoma setting has grown and both the $\mathrm{CH}$ and $\mathrm{CRF}$ from the ORA were proven to have a role both in diagnosis and prognosis, ${ }^{125,126}$ with special attention in eyes with ocular hypertension or in normotension glaucoma patients. $^{16}$

As the Scheimpflug technology increased the complexity of corneal biomechanics evaluation, there is still a lack of data regarding the differential role of the various Corvis-derived DCRs in the glaucoma spectrum. However, besides the measurement of several DCRs, the Corvis technology was validated by Vinciguerra et $\mathrm{al}^{127}$ for an IOP measurement with reduced biomechanical effect in the form of the aforementioned bIOP and, more recently, this was shown to be the most accurate form of measure the truth intraocular pressure in ex vivo studies with human eyes. ${ }^{128}$ Moreover, the novel DCR parameters and the bIOP are suggested nowadays as a new risk factor for the development of $\mathrm{NTG}^{129,130}$ and functional progression in $\mathrm{POAG},{ }^{130}$ but the evidence is still poor.

Recent data suggest that corneal biomechanical properties are related with axial length in high myopic eyes. $^{40,41}$ In fact, these eyes have significantly thinner lamina cribrosa than non-highly myopic eyes, which can increase the translaminar pressure gradient at a given intraocular pressure and may explain the increased susceptibility to glaucoma. ${ }^{131}$ The advent of multimodality in ophthalmology has helped to describe the relationship between high myopia and POAG in recent years. However, the causal relationship between these two entities is still controversial. ${ }^{132}$ 


\section{Corneal Biomechanics and Other Ocular Diseases (AION and Vascular Occlusions)}

The lamina cribrosa (LC) hypothetically plays a key role in the optic nerve and retinal vascular pathologies, as it is a local of anastomotic susceptibility and all main vessels pass through it. If corneal biomechanics is valued as a non-invasive biomarker of the LC structure, as described above, it makes sense to study its role in these entities. It is reported in the literature the association of central corneal thickness (CCT) and central retinal vein occlusion $(\mathrm{CRVO})^{133}$ but there are no data regarding corneal biomechanics itself. Additionally, high intraocular pressure, on the other hand, has been implicated as a risk factor many years before. ${ }^{134}$

The anterior ischemic optic neuropathy (AION) pathophysiology, by concept, includes hypoperfusion of the small vessels surrounding the optic disc. In contrast to glaucomatous eyes, the LC was shown to be anatomically normal in the eyes who underwent an AION event ${ }^{135}$ compared with controls and, in contrast to CRVO it was reported the lack of association with CCT. ${ }^{136}$ Besides the idea of shared pathophysiology, AION and NTG eyes were recently shown to differ regarding LC morphology, given rise to other possible factors like LC biomechanics behavior studied by the ORA. ${ }^{137}$ However, there are no data from the assessment of the DCRs or bIOP with Scheimplflug technology. Given this, the study of both the DCRs and the bIOP with the Corvis in the eyes with RVO or AION can be of utmost importance to increase the capability of risk prediction.

\section{Corneal Biomechanics and Age-Related Macular Degeneration (AMD)}

Bruch membrane $(\mathrm{BM})$ is elastin- and collagen-rich extracellular matrix (ECM), sharing most of the components with the corneal tissue. This membrane acts as a barrier between retinal pigment epithelium (RPE) and choriocapillaris (CC), playing an important role both in normal physiology and pathological processes like choroidal neovascularization $(\mathrm{CNV})$. As the impairment of BM properties has a pivotal role for the function of the photoreceptor (PR)-RPE-BM-CC unit, it forms the basis of the current pathophysiological paradigm in AMD. ${ }^{138}$ Accumulating evidence suggests that the structure and function of $\mathrm{BM}$ are unique to each human individual at a given age and, therefore, uniquely affect the progression of ocular disease. ${ }^{139,140}$ Increased CH and CRF by the ORA in eyes with AMD, particularly in those with CNV was reported years ago. ${ }^{141}$ However, there are no reports about the study of corneal biomechanics with the Scheimpflug technology in those patients. As the mechanisms of AMD progression to different late forms are not completely established and given the idea of the corneal biomechanics as a possible surrogate biomarker of BM tissue characteristics, it can play a role both in evolving risk prediction models and in the study of novel preventive and therapeutic modalities.

\section{Corneal Biomechanics and Angioid Streaks/Pseudoxanthoma Elasticum}

Angioid streaks (AS) result from crack-like breaks in BM, which is abnormal in its structural composition, with extensive calcification and thickening, predisposing to these localized areas of rupture. It can occur secondary to blunt trauma or spontaneously and can be associated with several systemic conditions. While the spectrum of associations is wide, the most common are usually described with the mnemonic PEPSI (Pseudoxanthoma elasticum (PXE), Ehler-Danlos syndrome, Paget's disease of bone, Sickle cell disease and other hemoglobinopathies, Idiopathic). ${ }^{142}$ PXE is a rare genetic disorder characterized by ectopic tissue mineralization with elastorrhexia and progressive fragmentation of elastic fibers primarily affecting the skin, the retina, and the cardiovascular system. Alterations in the ECM of the vessel walls leading to stiffening were reported in the literature. ${ }^{143}$ In the posterior eye, there is the mineralization of the elastic fibers, loss of elasticity, and enhanced calcification, leading to the characteristic AS, with serious risk of early-onset CNV. ${ }^{144}$ Besides the probable ubiquitous alterations in connective tissues, there are no reports about corneal tissue studies in these patients.

Given the most visual threatening complication is the $\mathrm{CNV}$ and understanding the process as an exponentiation of the RPE-BM-CC complex alterations, the study of corneal biomechanics can play a role not only in the aforementioned risk prediction but also in increasing knowledge about AMD pathophysiology itself. Additionally, it can be of value in gene therapy studies among these systemic entities. Recently, an association between corneal biomechanical properties and the number of anti-VEGF injections in these eyes was highlighted, ${ }^{145}$ 
but more studies are needed in order to address the potential usefulness of these properties in risk prediction.

\section{Conclusion}

Since biomechanics is a ubiquitous characteristic of biologic tissues, the non-invasive and rapid acquisition of data from corneal biomechanics can be of value in systemic diseases. While the application of data from corneal biomechanics is evolving in many areas of ophthalmology, there are fields in which data are still scarce and more studies are needed. The application of ultra-high-speed Scheimpflug imaging technology during non-contact tonometry associated with data analysis by artificial intelligence methods can be mainstays for the present and future transformation in this field.

\section{Disclosure}

Dr Renato Ambrosio Jnr report personal fees from Oculus, during the conduct of the study. The authors report no other conflicts of interest in this work.

\section{References}

1. Humphrey J. Continuum biomechanics of soft biological tissues. Proc R Soc London Series A. 2003;459:3-46

2. Humphrey J. Continuum thermomechanics and the clinical treatment of disease and injury. Appl Mech Rev. 2003;56(2):231-260. doi: $10.1115 / 1.1536177$

3. Provenzano PP, Lakes RS, Corr DT, Vanderby R Jr. Application of nonlinear viscoelastic models to describe ligament behavior. Biomech Model Mechanobiol. 2002;1(1):45-57. doi:10.1007/ s10237-002-0004-1

4. De Stefano VS, Dupps WJ Jr. Biomechanical diagnostics of the cornea. Int Ophthalmol Clin. 2017;57(3):75-86. doi:10.1097/ IIO.0000000000000172

5. Hamilton KE, Pye DC. Young's modulus in normal corneas and the effect on applanation tonometry. Optom Vis Sci. 2008;85 (6):445-450. doi:10.1097/OPX.0b013e3181783a70

6. Liu J, Qi H. Dissipated energy function, hysteresis and precondition of a viscoelastic solid model. Nonlinear Anal Real World Appl. 2010;11(2):907-912. doi:10.1016/j.nonrwa.2009.01.033

7. Dupps WJ Jr, Wilson SE. Biomechanics and wound healing in the cornea. Exp Eye Res. 2006;83(4):709-720. doi:10.1016/j. exer.2006.03.015

8. Jue B, Maurice DM. The mechanical properties of the rabbit and human cornea. J Biomech. 1986;19(10):847-853. doi:10.1016/ 0021-9290(86)90135-1

9. Seiler T, Matallana M, Sendler S, Bende T. Does Bowman's layer determine the biomechanical properties of the cornea? Refract Corneal Surg. 1992;8(2):139-142.

10. Hoeltzel DA, Altman P, Buzard K, Choe K. Strip extensiometry for comparison of the mechanical response of bovine, rabbit, and human corneas. $J$ Biomech Eng. 1992;114(2):202-215. doi: $10.1115 / 1.2891373$

11. Ortiz D, Piñero D, Shabayek MH, Arnalich-Montiel F, Alió JL. Corneal biomechanical properties in normal, post-laser in situ keratomileusis, and keratoconic eyes. J Cataract Refract Surg. 2007;33(8):1371-1375. doi:10.1016/j.jcrs.2007.04.021
12. González-Méijome JM, Villa-Collar C, Queirós A, Jorge J, Parafita MA. Pilot study on the influence of corneal biomechanical properties over the short term in response to corneal refractive therapy for myopia. Cornea. 2008;27(4):421-426. doi:10.1097/ ICO.0b013e318164e $49 \mathrm{~d}$

13. Kirwan C, O'Keefe M. Corneal hysteresis using the Reichert ocular response analyser: findings pre- and post-LASIK and LASEK. Acta Ophthalmol. 2008;86(2):215-218. doi:10.1111/ j.1600-0420.2007.01023.x

14. Salomão MQ, Hofling-Lima AL, Gomes Esporcatte LP, et al. The role of corneal biomechanics for the evaluation of ectasia patients. Int J Environ Res Public Health. 2020;17(6). doi:10.3390/ ijerph17062113.

15. Esporcatte LPG, Salomao MQ, Lopes BT, et al. Biomechanical diagnostics of the cornea. Eye Vis (Lond). 2020;7(1):9. doi:10.1186/s40662-020-0174-x

16. Grise-Dulac A, Saad A, Abitbol O, et al. Assessment of corneal biomechanical properties in normal tension glaucoma and comparison with open-angle glaucoma, ocular hypertension, and normal eyes. J Glaucoma. 2012;21(7):486-489. doi:10.1097/ IJG.0b013e318220daf0

17. Luce DA. Determining in vivo biomechanical properties of the cornea with an ocular response analyzer. $J$ Cataract Refract Surg. 2005;31(1):156-162. doi:10.1016/j.jcrs.2004.10.044

18. Fontes BM, Ambrosio R Jr, Alonso RS, Jardim D, Velarde GC, Nose W. Corneal biomechanical metrics in eyes with refraction of -19.00 to $+9.00 \mathrm{D}$ in healthy Brazilian patients. $J$ Refract Surg. 2008;24(9):941-945. doi:10.3928/1081597X-20081101-14

19. Ambrósio R Jr, Nogueira LP, Caldas DL, et al. Evaluation of corneal shape and biomechanics before LASIK. Int Ophthalmol Clin. 2011;51(2):11-38. doi:10.1097/IIO.0b013e31820f1d2d

20. Fontes BM, Ambrosio R Jr, Velarde GC, Nose W. Ocular response analyzer measurements in keratoconus with normal central corneal thickness compared with matched normal control eyes. J Refract Surg. 2011;27(3):209-215. doi:10.3928/ 1081597X-20100415-02

21. Glass DH, Roberts CJ, Litsky AS, Weber PA. A viscoelastic biomechanical model of the cornea describing the effect of viscosity and elasticity on hysteresis. Invest Ophthalmol Vis Sci. 2008;49(9):3919-3926. doi:10.1167/iovs.07-1321

22. Piñero DP, Alcón N. In vivo characterization of corneal biomechanics. J Cataract Refract Surg. 2014;40(6):870-887. doi:10.1016/j.jcrs.2014.03.021

23. Ambrósio JR, Ramos I, Luz A, et al. Dynamic ultra high speed Scheimpflug imaging for assessing corneal biomechanical properties. Rev Bras Oftalmol. 2013;72(2):99-102. doi:10.1590/ S0034-72802013000200005

24. Koprowski R, Ambrósio R Jr, Reisdorf S. Scheimpflug camera in the quantitative assessment of reproducibility of high-speed corneal deformation during intraocular pressure measurement. J Biophoton. 2015;8(11-12):968-978. doi:10.1002/ jbio. 201400137

25. Hashemi H, Asgari S, Mortazavi M, Ghaffari R. Evaluation of corneal biomechanics after excimer laser corneal refractive surgery in high myopic patients using dynamic Scheimpflug technology. Eye Contact Lens. 2017;43(6):371-377. doi:10.1097/ICL.0000000000000280

26. Salvetat ML, Zeppieri M, Tosoni C, Felletti M, Grasso L, Brusini P. Corneal deformation parameters provided by the Corvis-ST Pachy-tonometer in healthy subjects and glaucoma patients. J Glaucoma. 2015;24(8):568-574. doi:10.1097/ IJG.0000000000000133

27. Lanza M, Iaccarino S, Bifani M. In vivo human corneal deformation analysis with a Scheimpflug camera, a critical review. J Biophoton. 2016;9(5):464-477. doi:10.1002/jbio.201500233 
28. Tanter M, Touboul D, Gennisson JL, Bercoff J, Fink M. Highresolution quantitative imaging of cornea elasticity using supersonic shear imaging. IEEE Trans Med Imaging. 2009;28 (12):1881-1893. doi:10.1109/TMI.2009.2021471

29. Dupps WJ Jr, Netto MV, Herekar S, Krueger RR. Surface wave elastometry of the cornea in porcine and human donor eyes. $J$ Refract Surg. 2007;23(1):66-75. doi:10.3928/1081-597X20070101-11

30. Ford MR, Dupps WJ Jr, Rollins AM, Roy AS, Hu Z. Method for optical coherence elastography of the cornea. J Biomed Opt. 2011;16(1):016005. doi:10.1117/1.3526701

31. Seiler TG, Shao P, Eltony A, Seiler T, Yun SH. Brillouin spectroscopy of normal and keratoconus corneas. Am J Ophthalmol. 2019;202:118-125. doi:10.1016/j.ajo.2019.02.010

32. Lee H, Kang DSY, Ha BJ, et al. Biomechanical properties of the cornea using a dynamic Scheimpflug analyzer in healthy eyes. Yonsei Med J. 2018;59(9):1115-1122. doi:10.3349/ ymj.2018.59.9.1115

33. Valbon BF, Ambrósio R Jr, Fontes BM, Luz A, Roberts CJ, Alves MR. Ocular biomechanical metrics by CorVis ST in healthy Brazilian patients. J Refract Surg. 2014;30(7):468-473. doi:10.3928/1081597X-20140521-01

34. Salouti R, Bagheri M, Shamsi A, Zamani M. Corneal parameters in healthy subjects assessed by Corvis ST. J Ophthalmic Vis Res. 2020;15(1):24-31.

35. Huang Y, Lin S, Ma D, et al. Corneal biomechanical properties and associated factors in school-age children. Eye Sci. 2013;28 (1):34-39.

36. Elsheikh A, Geraghty B, Rama P, Campanelli M, Meek K. Characterization of age-related variation in corneal biomechanical properties. $\quad J \quad R \quad$ Soc Interface. 2010;7(51):1475-1485. doi:10.1098/rsif.2010.0108

37. Valbon BF, Ambrósio R, Fontes BM, Alves MR. Effects of age on corneal deformation by non-contact tonometry integrated with an ultra-high-speed (UHS) Scheimpflug camera. J Arq Bras Oftalmol. 2013;76(4):229-232. doi:10.1590/S000427492013000400008

38. Orr JB, Zvirgzdina M, Wolffsohn J. The influence of age, ethnicity, eye/body size and diet on corneal biomechanics. Invest Ophthalmol Vis Sci. 2017;58(8):1131.

39. Asaoka R, Nakakura S, Tabuchi $\mathrm{H}$, et al. The relationship between Corvis ST tonometry measured corneal parameters and intraocular pressure, corneal thickness and corneal curvature. PLoS One. 2015;10(10):e0140385. doi:10.1371/journal. pone. 0140385

40. Tubtimthong A, Chansangpetch S, Ratprasatporn $\mathrm{N}$, et al. Comparison of corneal biomechanical properties among axial myopic, nonaxial myopic, and nonmyopic eyes. Biomed Res Int. 2020;2020:8618615. doi:10.1155/2020/8618615

41. Wang J, Li Y, Jin Y, Yang X, Zhao C, Long Q. Corneal biomechanical properties in myopic eyes measured by a dynamic Scheimpflug analyzer. $J$ Ophthalmol. 2015;2015:1-8. doi:10.1155/2015/985071

42. Sarici AM, Yuksel Elgin C, Dikkaya F. Effect of fasting on corneal biomechanical and structural parameters. Curr Eye Res. 2016;41(7):908-912. doi:10.3109/02713683.2015.1080279

43. Long Q, Wang J, Yang X, Jin Y, Ai F, Li Y. Assessment of Corneal Biomechanical Properties by CorVis ST in Patients with Dry Eye and in Healthy Subjects. $J$ Ophthalmol. 2015;2015:380624. doi:10.1155/2015/380624

44. Singh M, Han Z, Li J, et al. Quantifying the effects of hydration on corneal stiffness with noncontact optical coherence elastography. J Cataract Refract Surg. 2018;44(8):1023-1031. doi:10.1016/j.jcrs.2018.03.036
45. Salouti R, Khalili MR, Zamani M, Ghoreyshi M, Nowroozzadeh MH. Assessment of the changes in corneal biomechanical properties after collagen cross-linking in patients with keratoconus. J Curr Ophthalmol. 2019;31(3):262-267. doi:10.1016/j.joco.2019.02.002

46. Sahin A, Bayer A, Ozge G, Mumcuoğlu T. Corneal biomechanical changes in diabetes mellitus and their influence on intraocular pressure measurements. Invest Ophthalmol Vis Sci. 2009;50 (10):4597-4604. doi:10.1167/iovs.08-2763

47. Goldich Y, Barkana Y, Gerber Y, et al. Effect of diabetes mellitus on biomechanical parameters of the cornea. $J$ Cataract Refract Surg. 2009;35(4):715-719. doi:10.1016/j.jcrs.2008.12.013

48. Ramm L, Herber R, Spoerl E, Pillunat LE, Terai N. Measurement of corneal biomechanical properties in diabetes mellitus using the ocular response analyzer and the Corvis ST. Cornea. 2019;38 (5):595-599. doi:10.1097/ICO.0000000000001879

49. Xu J, Shi G-P. Vascular wall extracellular matrix proteins and vascular diseases. Biochim Biophys Acta Mol Basis Dis. 2014;1842(11):2106-2119. doi:10.1016/j.bbadis.2014.07.008

50. Ponticos M, Partridge T, Black CM, Abraham DJ, Bou-Gharios G. Regulation of collagen Type I in vascular smooth muscle cells by competition between Nkx2.5 and SEF1/ZEB1. Mol Cell Biol. 2004;24(14):6151-6161. doi:10.1128/MCB.24.14.6151-6161.2004

51. Ciulla T, Bracha P, Pollack J, Williams D. Real-world outcomes of anti-vascular endothelial growth factor therapy in diabetic macular edema in the United States. Ophthalmol Retina. 2018;2.

52. Lim L, Cheung N, Gazzard G, Chan Y, Wong TY, Saw S-M. Corneal biomechanical properties and retinal vascular caliber in children. Invest Ophthalmol Vis Sci. 2008;50:121-125. doi:10.1167/iovs.08-2352

53. Yazıcı AT, Kara N, Yüksel K, et al. The biomechanical properties of the cornea in patients with systemic lupus erythematosus. Eye. 2011;25(8):1005-1009. doi:10.1038/eye.2011.99

54. Can ME, Erten S, Can GD, Cakmak HB, Sarac O, Cagil N. Corneal biomechanical properties in rheumatoid arthritis. Eye Contact Lens. 2015;41(6):382-385. doi:10.1097/ ICL. 0000000000000142

55. Mahendradas P, Francis M, Vala R, et al. Quantification of ocular biomechanics in ocular manifestations of systemic autoimmune diseases. Ocul Immunol Inflamm. 2019;27(7):1127-1137. doi:10.1080/09273948.2018.1501491

56. Kara N, Bozkurt E, Baz O, et al. Corneal biomechanical properties and intraocular pressure measurement in Marfan patients. $J$ Cataract Refract Surg. 2012;38(2):309-314. doi:10.1016/j. jcrs.2011.08.036

57. Long Q, Wang J, Yang X, Jin Y, Ai F, Li Y. Assessment of corneal biomechanical properties by CorVis ST in patients with dry eye and in healthy subjects. $J$ Ophthalmol. 2015;2015:1-7.

58. Long Q, Wang J-Y, Xu D, Li Y. Comparison of corneal biomechanics in Sjögren's syndrome and non-Sjögren's syndrome dry eyes by Scheimpflug based device. Int $J$ Ophthalmol. 2017;10:711-716. doi:10.18240/ijo.2017.05.08

59. Shetty R, Kaweri L, Pahuja N, et al. Current review and a simplified "five-point management algorithm" for keratoconus. Indian $J$ Ophthalmol. 2015;63:46-53. doi:10.4103/03014738.151468

60. Zhang XH, Li X. Effect of rigid gas permeable contact lens on keratoconus progression: a review. Int J Ophthalmol. 2020;13 (7):1124-1131. doi:10.18240/ijo.2020.07.17

61. Radaie-Moghadam S, Hashemi H, Jafarzadehpur E, Yekta A, Khabazkhoob M, Research V. Corneal biomechanical changes following toric soft contact lens wear. J Ophthal Vis Res. 2016;11(2):131-135. doi:10.4103/2008-322X.183921 
62. Kissner A, Boehm AG, Pillunat LE, Spoerl E. Effect of soft contact lens wear on corneal biomechanical properties. Invest Ophthalmol Vis Sci. 2009;50(13):1753.

63. Shokrollahzadeh F, Hashemi H, Jafarzadehpour E, Mirzajani A, Khabazkhoob M, Asgari S. Corneal biomechanics after rigid gas permeable contact lens wear in keratoconus eyes. J Eye Sci. 2016;1:25. doi:10.21037/jes.2016.07.01

64. Ambrósio R Jr, Lopes B, Amaral J, et al. Keratoconus: break of paradigms and contradictions of a new subspecialty. J Rev Bras Oftalmol. 2019;78:81-85.

65. Sedaghat M, Ostadi-Moghadam $\mathrm{H}$, Jabbarvand $\mathrm{M}$, Askarizadeh F, Momeni Moghaddam H, Narooie Noori F. Corneal hysteresis and corneal resistance factor in pellucid marginal degeneration. $J$ Curr Ophthalmol. 2017;30. doi:10.1016/j.joco.2017.08.002

66. Ambrósio R Jr., Correia FF, Lopes B, et al. Corneal biomechanics in ectatic diseases: refractive surgery implications. Open Ophthalmol J. 2017;11(1):176-193. doi:10.2174/ 1874364101711010176

67. Salomão M, Hoffling-Lima A, Lopes B, et al. Recent developments in keratoconus diagnosis. Expert Rev Ophthalmol. 2018;13 (6):329-341. doi:10.1080/17469899.2018.1555036

68. Bao F, Geraghty B, Wang Q, Elsheikh A. Consideration of corneal biomechanics in the diagnosis and management of keratoconus: is it important? Eye Vis. 2016;3(1). doi:10.1186/ s40662-016-0048-4

69. Steinberg J, Katz T, Lücke K, Frings A, Druchkiv V, Linke SJ. Screening for keratoconus with new dynamic biomechanical in vivo Scheimpflug analyses. Cornea. 2015;34(11):1404-1412. doi:10.1097/ICO.0000000000000598

70. Ambrosio R Jr, Lopes BT, Faria-Correia F, et al. Integration of Scheimpflug-based corneal tomography and biomechanical assessments for enhancing ectasia detection. J Refract Surg. 2017;33(7):434-443. doi:10.3928/1081597X-20170426-02

71. Wollensak G, Spoerl E, Seiler T. Riboflavin/ultraviolet-a-induced collagen crosslinking for the treatment of keratoconus. $\mathrm{Am}$ $J$ Ophthalmol. 2003;135(5):620-627. doi:10.1016/S0002-9394(02) 02220-1

72. Spoerl E, Terai N, Scholz F, Raiskup F, Pillunat LE. Detection of biomechanical changes after corneal cross-linking using ocular response analyzer software. J Refract Surg. 2011;27(6):452-457. doi:10.3928/1081597X-20110106-01

73. Gkika M, Labiris G, Giarmoukakis A, Koutsogianni A, Kozobolis V. Evaluation of corneal hysteresis and corneal resistance factor after corneal cross-linking for keratoconus. Graefes Arch Clin Exp Ophthalmol. 2012;250(4):565-573. doi:10.1007/ s00417-011-1897-0

74. De Bernardo M, Capasso L, Lanza M, et al. Long-term results of corneal collagen crosslinking for progressive keratoconus. J Optom. 2015;8(3):180-186. doi:10.1016/j.optom.2014.05.006

75. Salman A. Corneal biomechanical and anterior chamber parameters variations after 1-year of transepithelial corneal collagen cross linking in eyes of children with keratoconus. Middle East Afr J Ophthalmol. 2015;23.

76. Bak-Nielsen S, Pedersen IB, Ivarsen A, Hjortdal J. Dynamic Scheimpflug-based assessment of keratoconus and the effects of corneal cross-linking. J Refract Surg. 2014;30(6):408-414. doi:10.3928/1081597X-20140513-02

77. Hashemi H, Asgari S, Mehravaran S, Miraftab M, Ghaffari R, Fotouhi A. Corneal biomechanics after accelerated cross-linking: comparison between 18 and $9 \mathrm{~mW} / \mathrm{cm}^{2}$ protocols. J Refract Surg. 2017;33(8):558-562. doi:10.3928/ 1081597X-20170621-04
78. Tomita M, Mita M, Huseynova T. Accelerated versus conventional corneal collagen crosslinking. J Cataract Refract Surg. 2014;40(6):1013-1020. doi:10.1016/j.jcrs.2013.12.012

79. Kling S, Marcos S. Effect of hydration state and storage media on corneal biomechanical response from in vitro inflation tests. J Refract Surg. 2013;29(7):490-497. doi:10.3928/1081597X-20130617-08

80. Vega-Estrada A, Alio JL. The use of intracorneal ring segments in keratoconus. Eye Vis. 2016;3(1):8. doi:10.1186/s40662-0160040-z

81. Torquetti L, Berbel RF, Ferrara P. Long-term follow-up of intrastromal corneal ring segments in keratoconus. J Cataract Refract Surg. 2009;35(10):1768-1773. doi:10.1016/j.jcrs.2009.05.036

82. Vega-Estrada A, Alió JL, Brenner LF, Burguera N. Outcomes of intrastromal corneal ring segments for treatment of keratoconus: five-year follow-up analysis. J Cataract Refract Surg. 2013;39 (8):1234-1240. doi:10.1016/j.jcrs.2013.03.019

83. Daas L. Changes in biomechanical properties of keratoconic corneas following intracorneal ring segment (ICRS) implantation. Acta Ophthalmol. 2019;97(S263).

84. Park SE, Tseng M, Lee JK. Effectiveness of intracorneal ring segments for keratoconus. Curr Opin Ophthalmol. 2019;30 (4):220-228. doi:10.1097/ICU.0000000000000582

85. d'Azy CB, Pereira B, Chiambaretta F, Dutheil F. Efficacy of different procedures of intra-corneal ring segment implantation in keratoconus: a systematic review and meta-analysis. Transl Vis Sci Technol. 2019;8(3):38. doi:10.1167/tvst.8.3.38

86. Ambrósio JR, Borges JS, Costa-Ferreira C, et al. Implant of intrastromal corneal ring segments in keratoconus: results and correlations with preoperative corneal biomechanics. J Rev Bras Oftalmol. 2012;71:89-99. doi:10.1590/S003472802012000200004

87. Pinero D, Alió J, Barraquer R, Michael R. Corneal biomechanical changes after intracorneal ring segment implantation in keratoconus. Cornea. 2012;31(5):491-499. doi:10.1097/ ICO.0b013e31821 ee9f4

88. Sedaghat M-R, Momeni-Moghaddam H, Piñero DP, et al. Predictors of successful outcome following intrastromal corneal ring segments implantation. Curr Eye Res. 2019;44(7):707-715. doi:10.1080/02713683.2019.1594945

89. Feizi S, Montahai T, Moein H-R. Graft biomechanics following three corneal transplantation techniques. J Ophthalmic Vis Res. 2015;10(3):238. doi:10.4103/2008-322X.170347

90. Faramarzi A, Feizi S, Najdi D, Ghiasian L, Karimian F. Changes in corneal biomechanical properties after descemet stripping automated endothelial keratoplasty for pseudophakic bullous keratopathy. Cornea. 2016;35(1):20-24. doi:10.1097/ ICO.0000000000000684

91. Shilova NF, Nahum Y, Adler A, et al. Comparative analysis of biomechanical parameters of the corneas following Descemet membrane endothelial keratoplasty and contralateral healthy corneas. Graefes Arch Clin Exp Ophthalmol. 2019;257 (9):1925-1929. doi:10.1007/s00417-019-04387-y

92. Ziaei M, Vellara HR, Gokul A, Ali NQ, McGhee CNJ, Patel DV. Comparison of corneal biomechanical properties following penetrating keratoplasty and deep anterior lamellar keratoplasty for keratoconus. Clin Experiment Ophthalmol. 2020;48(2):174-182. doi:10.1111/ceo.13677

93. Hugo J, Granget E, Yin GH, Sampo M, Hoffart L. Intraocular pressure measurements and corneal biomechanical properties using a dynamic Scheimpflug analyzer, after several keratoplasty techniques, versus normal eyes. J Fr Ophtalmol. 2018;41 (1):30-38. doi:10.1016/j.jfo.2017.06.006 
94. Torres-Netto EA, Kling S, Spiru B, Sekundo W, Hafezi F. The relevance of Bowman's layer in corneal biomechanics. Invest Ophthalmol Vis Sci. 2019;60(9):6808.

95. Dragnea DC, Birbal R, Ham L, et al. Bowman layer transplantation in the treatment of keratoconus. Eye Vis. 2018;5(1):24. doi:10.1186/s40662-018-0117-y

96. Hirasawa K, Nakakura S, Nakao Y, et al. Changes in corneal biomechanics and intraocular pressure following cataract surgery. Am J Ophthalmol. 2018;195:26-35. doi:10.1016/j. ajo.2018.07.025

97. Wallace HB, Misra SL, Li SS, McKelvie J. Biomechanical changes in the cornea following cataract surgery: a prospective assessment with the Corneal Visualisation Scheimpflug Technology. Clin Experiment Ophthalmol. 2019;47(4):461-468. doi:10.1111/ceo.13451

98. Ali M, Kamiya K, Shimizu K, Igarashi A, Ishii R. Clinical evaluation of corneal biomechanical parameters after posterior chamber phakic intraocular lens implantation. Cornea. 2014;33(5):470-474. doi:10.1097/ICO.00000000000 00088

99. Spadea L, Cantera E, Cortes M, Conocchia NE, Stewart CW. Corneal ectasia after myopic laser in situ keratomileusis: a long-term study. Clin Ophthalmol. 2012;6:1801-1813. doi:10.2147/OPTH.S37249

100. Ambrósio R Jr. Post-LASIK Ectasia: twenty years of a Conundrum. Semin Ophthalmol. 2019;34(2):66-68. doi:10.1080/ 08820538.2019.1569075

101. Binder PS, Lindstrom RL, Stulting RD, et al. Keratoconus and corneal ectasia after LASIK. J Cataract Refract Surg. 2005;31 (11):2035-2038. doi:10.1016/j.jcrs.2005.12.002

102. Randleman JB, Trattler WB, Stulting RD. Validation of the Ectasia Risk Score System for preoperative laser in situ keratomileusis screening. Am J Ophthalmol. 2008;145(5):813-818. doi:10.1016/j.ajo.2007.12.033

103. Santhiago MR, Smadja D, Gomes BF, et al. Association between the percent tissue altered and post-laser in situ keratomileusis ectasia in eyes with normal preoperative topography. $\mathrm{Am}$ J Ophthalmol. 2014;158(1):87-95.e81. doi:10.1016/j. ajo.2014.04.002

104. Santhiago MR, Smadja D, Wilson SE, Krueger RR, Monteiro ML, Randleman JB. Role of percent tissue altered on ectasia after LASIK in eyes with suspicious topography. J Refract Surg. 2015;31(4):258-265. doi:10.3928/1081597X-20150319-05

105. Bohac M, Koncarevic M, Pasalic A, et al. Incidence and clinical characteristics of Post LASIK Ectasia: a review of over 30,000 LASIK cases. Semin Ophthalmol. 2018;33(7-8):869-877. doi:10.1080/08820538.2018.1539183

106. Roberts CJ, Dupps WJ Jr. Biomechanics of corneal ectasia and biomechanical treatments. J Cataract Refract Surg. 2014;40 (6):991-998. doi:10.1016/j.jcrs.2014.04.013

107. Vinciguerra R, Ambrosio R Jr, Elsheikh A, et al. Detection of keratoconus with a new biomechanical index. J Refract Surg. 2016;32(12):803-810. doi:10.3928/1081597X-20160629-01

108. Del Buey MA, Cristóbal JA, Ascaso FJ, Lavilla L, Lanchares E. Biomechanical properties of the cornea in Fuchs' corneal dystrophy. Invest Ophthalmol Vis Sci. 2009;50(7):3199-3202. doi:10.1167/iovs.08-3312

109. Clemmensen K, Hjortdal J. Intraocular pressure and corneal biomechanics in Fuchs' endothelial dystrophy and after posterior lamellar keratoplasty. Acta Ophthalmol. 2014;92(4):350-354. doi:10.1111/aos.12137

110. Tham YC, Li X, Wong TY, Quigley HA, Aung T, Cheng CY. Global prevalence of glaucoma and projections of glaucoma burden through 2040: a systematic review and meta-analysis. Ophthalmology. 2014;121(11):2081-2090. doi:10.1016/j. ophtha.2014.05.013
111. Kass MA, Heuer DK, Higginbotham EJ, et al. The Ocular Hypertension Treatment Study: a randomized trial determines that topical ocular hypotensive medication delays or prevents the onset of primary open-angle glaucoma. Arch Ophthalmol. 2002;120(6):701-713; discussion 829-730. doi:10.1001/ archopht.120.6.701

112. Trivli A, Koliarakis I, Terzidou C, et al. Normal-tension glaucoma: pathogenesis and genetics. Exp Ther Med. 2019;17 (1):563-574. doi:10.3892/etm.2018.7011

113. Sit AJ, Pruet CM. Personalizing intraocular pressure: target intraocular pressure in the setting of 24-hour intraocular pressure monitoring. Asia Pac J Ophthalmol. 2016;5(1):17-22. doi:10.1097/APO.0000000000000178

114. Strouthidis NG, Girard MJ. Altering the way the optic nerve head responds to intraocular pressure-a potential approach to glaucoma therapy. Curr Opin Pharmacol. 2013;13(1):83-89. doi:10.1016/j. coph.2012.09.001

115. Sigal IA, Ethier CR. Biomechanics of the optic nerve head. Exp Eye Res. 2009;88(4):799-807. doi:10.1016/j.exer.2009.02.003

116. Roberts MD, Sigal IA, Liang Y, Burgoyne CF, Downs JC. Changes in the biomechanical response of the optic nerve head in early experimental glaucoma. Invest Ophthalmol Vis Sci. 2010;51(11):5675-5684. doi:10.1167/iovs.10-5411

117. Roberts MD, Liang Y, Sigal IA, et al. Correlation between local stress and strain and lamina cribrosa connective tissue volume fraction in normal monkey eyes. Invest Ophthalmol Vis Sci. 2010;51(1):295-307. doi:10.1167/iovs.09-4016

118. Satekenova E, Ko MWL, Kim JR Investigation of the optic nerve head morphology influence to the optic nerve head biomechanics - patient specific model. Conference proceedings: Annual International Conference of the IEEE Engineering in Medicine and Biology Society IEEE Engineering in Medicine and Biology Society Annual Conference; 2019:5370-5373.

119. Girard MJ, Suh JK, Bottlang M, Burgoyne CF, Downs JC. Biomechanical changes in the sclera of monkey eyes exposed to chronic IOP elevations. Invest Ophthalmol Vis Sci. 2011;52 (8):5656-5669. doi:10.1167/iovs.10-6927

120. Yang $H$, Ren $R$, Lockwood $H$, et al. The connective tissue components of optic nerve head cupping in monkey experimental glaucoma part 1: global change. Invest Ophthalmol Vis Sci. 2015;56(13):7661-7678. doi:10.1167/iovs.15-17624

121. Grytz R, Meschke G, Jonas JB. The collagen fibril architecture in the lamina cribrosa and peripapillary sclera predicted by a computational remodeling approach. Biomech Model Mechanobiol. 2011;10 (3):371-382. doi:10.1007/s10237-010-0240-8

122. Ethier CR. Scleral biomechanics and glaucoma-a connection? Can J Ophthalmol. 2006;41(1):9-12, 14. doi:10.1016/S00084182(06)80060-8

123. Burgoyne CF, Downs JC, Bellezza AJ, Suh JK, Hart RT. The optic nerve head as a biomechanical structure: a new paradigm for understanding the role of IOP-related stress and strain in the pathophysiology of glaucomatous optic nerve head damage. Prog Retin Eye Res. 2005;24(1):39-73. doi:10.1016/j. preteyeres.2004.06.001

124. Helmy H, Leila M, Zaki AA. Corneal biomechanics in asymmetrical normal-tension glaucoma. Clin Ophthalmol. 2016;10:503-510.

125. Kaushik S, Pandav SS, Banger A, Aggarwal K, Gupta A. Relationship between corneal biomechanical properties, central corneal thickness, and intraocular pressure across the spectrum of glaucoma. Am J Ophthalmol. 2012;153(5):840-849.e842. doi:10.1016/j.ajo.2011.10.032

126. Potop V, Corbu C, Coviltir V, et al. The importance of corneal assessment in a glaucoma suspect - a review. Rom J Ophthalmol. 2019;63(4):321-326. doi:10.22336/rjo.2019.51 
127. Joda AA, Shervin MM, Kook D, Elsheikh A. Development and validation of a correction equation for Corvis tonometry. Comput Methods Biomech Biomed Engin. 2016;19(9):943-953. doi:10.1080/10255842.2015.1077515

128. Eliasy A, Chen KJ, Vinciguerra R, et al. Ex-vivo experimental validation of biomechanically-corrected intraocular pressure measurements on human eyes using the CorVis ST. Exp Eye Res. 2018;175:98-102. doi:10.1016/j.exer.2018.06.013

129. Miki A, Yasukura Y, Weinreb R, et al. Dynamic Scheimpflug ocular biomechanical parameters in untreated primary open angle glaucoma eyes. Invest Ophthalmol Vis Sci. 2020;61(4):19. doi:10.1167/iovs.61.4.19

130. Vinciguerra R, Rehman S, Vallabh NA, et al. Corneal biomechanics and biomechanically corrected intraocular pressure in primary open-angle glaucoma, ocular hypertension and controls. Br J Ophthalmol. 2020;104 (1):121-126. doi:10.1136/bjophthalmol-2018-313493

131. Jonas JB, Berenshtein E, Holbach L. Lamina cribrosa thickness and spatial relationships between intraocular space and cerebrospinal fluid space in highly myopic eyes. Invest Ophthalmol Vis Sci. 2004;45(8):2660-2665. doi:10.1167/iovs.03-1363

132. Chansangpetch S, Panpruk R, Manassakorn A, et al. Impact of myopia on corneal biomechanics in glaucoma and nonglaucoma patients. Invest Ophthalmol Vis Sci. 2017;58(12):4990. doi:10.1167/iovs.17-22219

133. Wanichwecharungruang B, Laophulsuk V, Sopitanont S, Vanichvaranont S, Harncharoen K. Central corneal thickness in the central retinal vein occlusion fellow eyes. J Med Assoc Thai. 2010;93(8):943-949.

134. Risk factors for central retinal vein occlusion. The Eye Disease Case-Control Study Group. Arch Ophthalmol. 1996;114 (5):545-554. doi:10.1001/archopht.1996.01100130537006

135. Fard MA, Afzali M, Abdi P, et al. Optic nerve head morphology in nonarteritic anterior ischemic optic neuropathy compared to open-angle glaucoma. Invest Ophthalmol Vis Sci. 2016;57 (11):4632-4640. doi:10.1167/iovs.16-19442

136. Jabaly-Habib H, Naftali M, Habib GJ. Central corneal thickness measurements in nonarteritic anterior ischemic optic neuropathy patients: a Controlled Study. J Ophthalmol. 2014;2014. doi:10.1155/2014/904373
137. Uysal BS, Yulek F, Nalcacioglu P, Sarac O, Yorgun MA, Cagil N. Can corneal biomechanical properties give clues about elasticity of optic nerve scleral component in nonarteritic anterior ischemic optic neuropathy? J Neuro-Ophthalmol. 2016;36(3):285-289. doi:10.1097/WNO.0000000000000406

138. Booij JC, Baas DC, Beisekeeva J, Gorgels TG, Bergen AA. The dynamic nature of Bruch's membrane. Prog Retin Eye Res. 2010;29(1):1-18. doi:10.1016/j.preteyeres.2009.08.003

139. Bhutto I, Lutty G. Understanding age-related macular degeneration (AMD): relationships between the photoreceptor/retinal pigment epithelium/Bruch's membrane/choriocapillaris complex. Mol Aspects Med. 2012;33(4):295-317. doi:10.1016/j.mam.2012.04.005

140. van Lookeren Campagne M, LeCouter J, Yaspan BL, Ye W. Mechanisms of age-related macular degeneration and therapeutic opportunities. J Pathol. 2014;232(2):151-164. doi:10.1002/path.4266

141. Cellini M, Pazzaglia A, Strobbe E, Gizzi C, Balducci N, Campos E. Corneal biomechanics in age-related macular degeneration. Can J Physiol Pharmacol. 2010;88(s246). doi:10.1139/Y10-036

142. Chatziralli I, Saitakis G, Dimitriou E, et al. ANGIOID STREAKS: a comprehensive review from pathophysiology to treatment. Retina (Philadelphia, Pa). 2019;39(1):1-11. doi:10.1097/IAE.0000000000002327

143. Germain DP, Boutouyrie P, Laloux B, Laurent S. Arterial remodeling and stiffness in patients with pseudoxanthoma elasticum. Arterioscler Thromb Vasc Biol. 2003;23(5):836-841. doi:10.1161/ 01.ATV.0000067428.19031.28

144. Germain DP. Pseudoxanthoma elasticum. Orphanet $J$ Rare Dis. 2017;12(1):85. doi:10.1186/s13023-017-0639-8

145. Asano S, Nakajima K, Kure K, et al. Corneal biomechanical properties are associated with the activity and prognosis of Angioid Streaks. Sci Rep. 2018;8(1):8130. doi:10.1038/s41598018-26430-4

146. Baptista PM, Marta AA, Marques JH, Abreu AC, Monteiro S, Menéres P, Pinto MDC The Role of Corneal Biomechanics in the Assessment of Ectasia Susceptibility Before Laser Vision Correction. Clin Ophthalmol. 2021;15:745-758. https://doi.org/ 10.2147/OPTH.S296744
Clinical Ophthalmology

\section{Publish your work in this journal}

Clinical Ophthalmology is an international, peer-reviewed journal covering all subspecialties within ophthalmology. Key topics include: Optometry; Visual science; Pharmacology and drug therapy in eye diseases; Basic Sciences; Primary and Secondary eye care; Patient Safety and Quality of Care Improvements. This journal is indexed on PubMed

\section{Dovepress}

Central and CAS, and is the official journal of The Society of Clinical Ophthalmology (SCO). The manuscript management system is completely online and includes a very quick and fair peer-review system, which is all easy to use. Visit http://www.dovepress.com/ testimonials.php to read real quotes from published authors. 